\title{
Considérations sur la deuxième mue des larves d'Ascaridia galli
}

\author{
par P. ARAUJO et Maria C. R. V. BRESSAN \\ Département de Parasitologie, Institut de Sciences biomédicales, \\ Université de São Paulo, Brésil.
}

\section{Résuméé.}

Chez des larves d'Ascaridia galli obtenues par éclosion artificielle, la présence de deux cuticules distinctes décollées du corps des larves est plus fréquente après 11 et 12 jours qu'après 10 et 14 jours d'incubation à la température de $25^{\circ} \mathrm{C}$. Ces cuticules indiquent que les larves de ce nématode effectuent deux mues avant l'éclosion et, par conséquent, que ses larves infestantes appartiennent au troisième stade du développement.

\section{Summary.}

Observations on the second moult of the larvae of Ascaridia galli.

In Ascaridia galli larvae artificially hatched after 11 and 12 days of incubation at $25^{\circ} \mathrm{C}$, in larger frequency than in larvae hatched either after 10 and after 14 days of incubation, two different cuticles detached from their bodies were observed. These two detached cuticles indicate that such larvae had undergone two moults before hatching and, consequently, that the infective stage of $A$. galli is the third larval stage.

\section{Introduction}

Ackert (1931), Alicata (1934), Roberts (1937) et Tugwell et Ackert (1952) ont affirmé que la larve infestante d'Ascaridia galli (nématode appartenant, selon les auteurs, à la famille Ascarididae ou à la famille Heterakidae) est la larve du deuxième stade.

Reçu le $1^{\bullet r}$ février 1977. 
Récemment, Herd et MacNaught (1975) n'ont observé qu'une seule mue chez des larves d'A. galli écloses artificiellement et ont également conclu que les larves infestantes de cette espèce appartiennent au deuxième stade. Ces auteurs ont examiné au moins 100 spécimens par jour, du dixième au vingtième jour d'incubation à la température de $30^{\circ} \mathrm{C}$.

Henner (1959), Thust (1968), Araujo (1971 a, $1972 a$ ) et Maung (1975) ont montré que chez des larves de diverses espèces d'ascaridines, deux mues sont effectuées dans l'œuf et que les larves infestantes sont les larves III.

Bain (1970) a vérifié que, à l'éclosion, les larves infestantes de l'Heterakidae Strongyluris brevicaudata se trouvent au troisième stade et a conclu, après l'analyse des cycles connus d'heterakides, que dans cette famille, les larves éclosent au troisième stade.

Graeiro (1973, observation inédite) a vérifié qu'au douzième jour d'incubation à la température de $25^{\circ} \mathrm{C}$, deux mues avaient eu lieu chez des larves d' $A$. galli avant l'éclosion.

En face de résultats si discordants, nous avons entrepris des recherches afin de reprendre les observations de Graeiro.

\section{Matériel et méthodes}

En partant d'exemplaires femelles d' $A$. galli, mesurant au moins $7,5 \mathrm{~cm}$ de long, récoltés chez des poulets récemment abattus, nous avons fait des « cultures » d'œufs, en effectuant, au préalable, le prélèvement des utérus et leur digestion par une solution de pepsine à $1 \%$, pour libérer les œufs. Ceux-ci ont été lavés plusieurs fois à l'eau de source et, ensuite, ils ont été placés dans des plaques de Petri, contenant de l'eau de source formolée (solution à $0,5 \%$ ) et incubés à la température de $25^{\circ} \mathrm{C}$.

Pour l'étude des larves, nous avons provoqué leur éclosion, du dixième au quatorzième jour d'incubation, par légère compression exercée sur des centaines d'œufs entre lame et lamelle, dans un milieu constitué d'eau de la «culture » et d'une solution saline (chlorure de sodium à $0,8 \%$ ). Nous avons réalisé les dessins des larves à la chambre claire et les micrographies au microscope à contraste de phase.

\section{Résultats}

Après 10 jours d'incubation, certaines des larves examinées, ayant éclos artificiellement dans un milieu constitué d'eau de la «culture», présentaient une petite calotte cuticulaire à l'extrémité antérieure. D'autres montraient, toujours à l'extrémité antérieure, une cuticule décollée du corps, contenant une tache réfringente près de la partie courbée de cette cuticule (fig. 1). D'autres larves, plus rares, présentaient deux cuticules distinctes décollées du corps, à l'extrémité antérieure (fig. 2). Chez celles-ci, nous avons observé, sur la première cuticule décollée (l'externe), la tache réfringente 

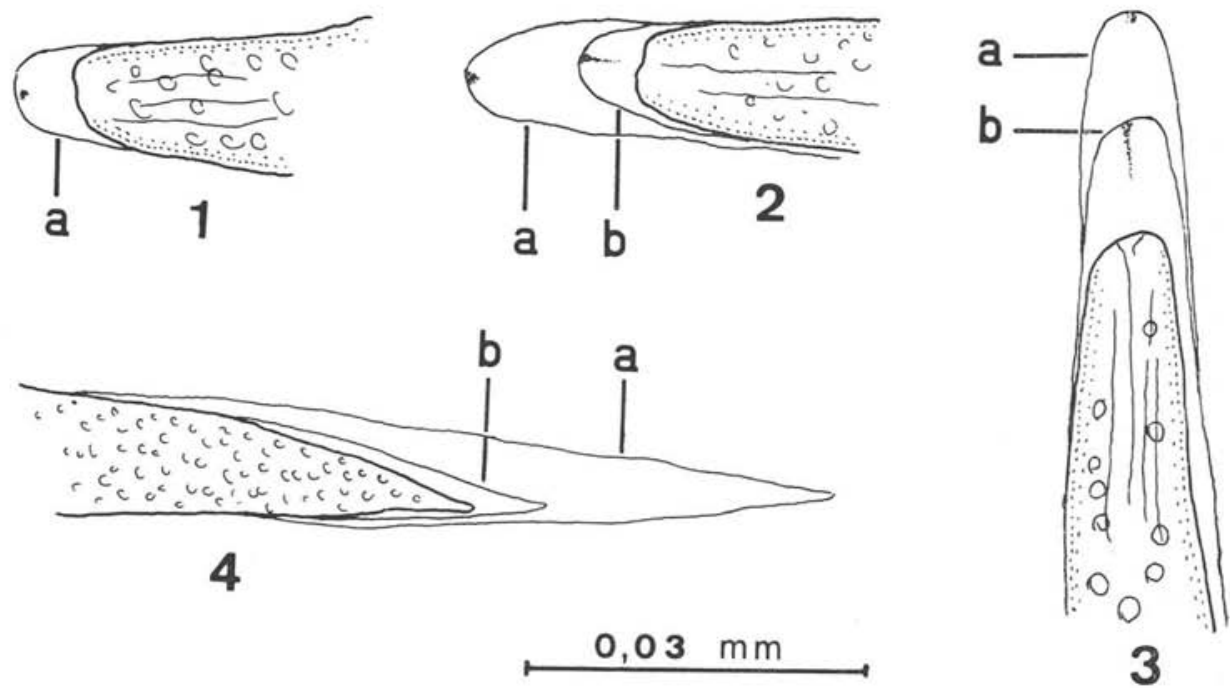

Fig. 1-4. - Extrémités antérieures (fig. 1-3) et postérieure (fig. 4) de larves d'A. galli obtenues par l'éclosion artificielle après dix jours (fig. 1 et 2), onze jours (fig. 3) et douze jcurs (fig. 4) d'incubation, montrant les cuticules du premier $(a)$ et du deuxième $(b)$ stades, partiellement décollées du corps de la larve. La figure 4 a été faite d'après un dessin de A. Graeiro (1973).
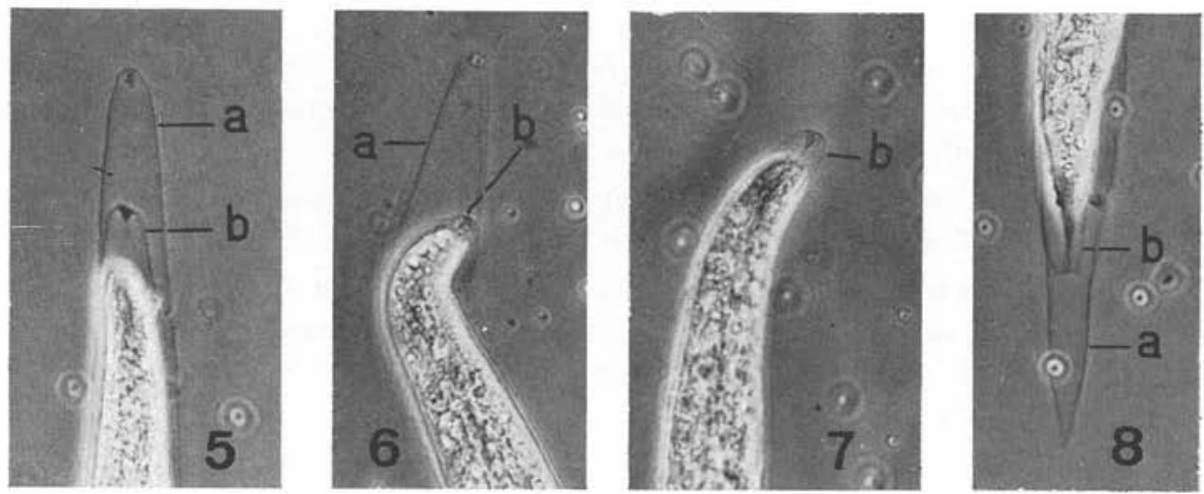

Fig. 5-8. - Extrémités antérieures (fig. 5-7) et postérieure (fig. 8) de larves d'A. galli obtenues par éclosion artificielle après onze jours d'incubation, montrant les cuticules du premier $(a)$ et du deuxième $(b)$ stades, partiellement décollées du corps de la larve.

ci-dessus mentionnée, et sur la seconde cuticule, nous avons vérifié la présence d'un filament épais dans sa partie initiale, contiguë à la cuticule décollée, devenant plus mince vers l'arrière, avec l'éloignement de l'extrémité antérieure. 
Considérant que le décollement cuticulaire marque la réalisation d'une mue, nous pouvons supposer : a) que les premières larves citées ci-dessus, c'est-à-dire, celles qui présentaient une calotte cuticulaire à l'extrémité antérieure, étaient au début du deuxième stade ; $b$ ) que les larves mentionnées en second lieu, avec une seule cuticule décollée du corps, étaient au deuxième stade ; c) que les larves mentionnées en dernier, celles qui montraient deux cuticules distinctes décollées du corps, étaient des larves au troisième stade du développement. La tache réfringente observée à l'extrémité antérieure de la première cuticule peut être interprétée comme l'orifice buccal et le filament observé sur la seconde cuticule, comme le revêtement cuticulaire de la lumière œsophagienne.

Après 11 et 12 jours d'incubation, certaines des larves obtenues par éclosion artificielle présentaient, également, un décollement des cuticules du premier et du deuxième stades, principalement à l'extrémité antérieure (fig. 3, 5 et 6). Sur les deux cuticules ont été observées les formations décrites ci-dessus, c'est-à-dire, la tache réfringente et le filament. D'autres larves montraient, aux extrémités antérieures (fig. 7) ou postérieure, une seule cuticule, celle du deuxième stade, décollée du corps de la larve. Dans ce laps de temps (11 et 12 jours d'incubation), les larves à deux cuticules distinctes décollées du corps ont été plus fréquemment rencontrées que pour 10 jours d'incubation. Un tel fait est dû, peut-être, à une plus forte résistance à la compression mécanique acquise par les larves au onzième et au douzième jour d'incubation et, probablement, à l'existence d'un plus grand nombre de larves au troisième stade que pour 10 jours d'incubation. On peut observer sur les figures 3 et 5 que la cuticule externe, celle du premier stade, présente l'extrémité antérieure arrondie, tandis que la cuticule interne, du deuxième stade, montre la même extrémité légèrement en forme de biseau comme l'extrémité orale de la larve. Après 11 et 12 jours d'incubation, nous avons observé de rares exemplaires avec deux cuticules décollées du corps à l'extrémité postérieure (fig. 4 et 8 ).

Les observations ci-dessus décrites ont été réalisées chez des larves, soit dans un milieu constitué d'eau de la «culture», soit dans une solution saline.

Après 14 jours d'incubation les larves observées, montraient en majorité une seule cuticule (celle du second stade) décollée du corps, ou se présentaient nues. Cependant, certaines des larves examinées, d'ailleurs très rares, montraient deux cuticules distinctes décollées du corps.

\section{Discussion et conclusion}

En plus des observations réalisées avec des larves écloses dans un milieu fait d'eau de la « culture », nous avons aussi examiné des larves écloses dans une solution saline, pour que soit exclue l'éventuelle action décollante de cuticule par l'eau de source, telle qu'elle fut observée par Araujo (1973) chez des larves d'Ascaris suum maintenues dans de l'eau de source pendant 6 heures, à la température de $37^{\circ} \mathrm{C}$. 
Herd et MacNaught (1975), n'observant qu'une seule cuticule décollée du corps des larves d'A. galli, écloses artificiellement, ont affirmé que la larve infestante appartient au deuxième stade, concordant ainsi avec d'autres auteurs qui ont étudié le cycle, partiel ou total, de cette espèce. Cependant, considérant : 1) que la «culture » d'œufs d'A. galli réalisée par Herd et MacNaught a été maintenue à la température de $30^{\circ} \mathrm{C}$; 2) que leurs examens ont été fait du dixième au vingtième jour d'incubation ; 3) que notre «culture » a été maintenue à la température de $25^{\circ} \mathrm{C}$; 4) finalement, que nous avons observé un plus grand nombre de larves présentant deux cuticules décollées du corps après 11 et 12 jours d'incubation, il nous semble probable que les larves examinées par Herd et MacNaught après 10 jours d'incubation, en raison de la température à laquelle la «culture » était maintenue $\left(5^{\circ} \mathrm{C}\right.$ plus haute que celle du milieu de notre «culture »), correspondaient, en développement, à nos larves examinées après 14 jours d'incubation, parmi lesquelles nous avons trouvé de très rares spécimens à deux cuticules décollées du corps. Cette hypothèse est renforcée par les résultats d'Alicata (1934), obtenus avec des œufs d' $A$. suum qui deviennent infestants après 16 jours d'incubation à $33^{\circ} \mathrm{C}$, et après 28 jours aux températures entre $22^{\circ} \mathrm{C}$ et $24^{\circ} \mathrm{C}$.

Quant aux mues effectuées par les larves d'A. galli pendant la phase parasitaire, certains aspects doivent être analysés :

Tugwell et Ackert (1952), chez des larves récoltées dans la muqueuse intestinale de poulet et préalablement exposées à l'action de la pepsine acide, ont observé la « deuxième » et la troisième mues, c'est-à-dire, celles qui assurent le passage du deuxième au troisième et du troisième au quatrième stades larvaires. D'autre part, chez des larves provenant du contenu intestinal, qui n'ont pas été soumises à l'action de la pepsine acide, ces auteurs ont observé seulement la mue située entre le troisième et le quatrième stades ; cependant, la «deuxième » mue, celle qui sépare le deuxième stade du troisième, a été considérée comme représentée par les modifications morphologiques semblables à celles des larves en train d'effectuer la «deuxième » mue, récoltées dans la muqueuse intestinale, c'est-à-dire les larves ayant été préalablement exposées à l'action de la pepsine acide.

Herd et MacNaught (1975), chez des larves récoltées dans le contenu intestinal d'oiseaux, et n'ayant pas été exposées à l'action de la pepsine acide, ont affirmé l'existence de la «deuxième » et de la troisième mues, en se fondant, soit sur l'observation d'un décollement cuticulaire, soit sur l'aspect morphologique des larves; ces auteurs n'ont pas mentionné chez laquelle des deux mues décrites ils ont détecté un décollement cuticulaire.

Cependant, Araujo (1973) a vérifié que l'action de la pepsine acide ( $\mathrm{pH}$ 1) ou simplement d'une solution d'acide chlorhydrique ( $\mathrm{pH}$ 1) sur des larves d'A. suum provoque un décollement cuticulaire, ce qui peut simuler une mue.

Ainsi, l'observation de Tugwell et Ackert (1952) concernant la «deuxième s mue chez des larves exposées à l'action de la pepsine acide, doit être réinterprétée comme étant le résultat probable d'un artéfact de technique.

D'autre part, Bain (1970) et Araujo (1971 b, $1972 b)$ ont constaté que les larves de $S$. brevicaudata et de Polydelphis quadrangularis, respectivement heterakide et asca- 
ride, présentent des modifications morphologiques accentuées pendant leur développement, entre le début et la fin du troisième stade. En outre, Araujo (1975) a relevé un dimorphisme sexuel considérable au niveau de l'ébauche génitale et de la queue des larves d' $A$. suum du troisième stade, 9 jours après l'infestation ; un tel dimorphisme n'a pas été remarqué chez des larves infestantes (au troisième stade) après l'éclosion, ou après les premiers jours d'infestation.

De cette façon, nous devons considérer aussi avec réserve les interprétations concernant la réalisation de la « deuxième » mue chez des larves d' $A$. galli n'ayant pas été soumises à l'action de la pepsine acide, aussi bien celle donnée par Tugwell et Ackert (1952), comme probablement celle de Herd et MacNaught (1975), fondée sur les modifications morphologiques des larves pendant leur développement.

De cet exposé, nous devons souligner l'exactitude des observations de Graeiro (1973), décédé en 1973, en ce qui concerne la réalisation de deux mues chez des larves d'A. galli dans l'œuf, et nous pouvons donc conclure que les larves infestantes de ce nématode appartiennent au troisième stade du développement.

\section{Bibliographie}

ACKerT (J. E.), 1931. - The morphology and life history of the fowl nematode Ascaridia lineata (Schneider). Parasitology, 23, 360-379.

Alicata (J.E.), 1934. - Observations on the period required for Ascaris eggs to reach infectivity. Proc. helminth. Soc. Wash., 1, 12.

Araujo (P.), 1971 a. - Considérations sur la deuxième mue des larves d'Ascarides parasites de serpents. Ann. Parasitol. hum. comp., 46, 605-612.

- - $1971 b$. - Observations sur le développement de l'ébauche génitale chez des larves du $3^{\circ}$ stade de Polydelphis quadrangularis (Schneider, 1866) (Nematoda: Ascaridoidea). Ann. Parasitol. hum. comp., 46, 699-707.

- - $1972 a$. - Observações pertinentes às primeiras ecdises de larvas de Ascaris lumbricoides, A. suum e Toxocara canis. Rev. Inst. Med. trop. S, Paulo, 14, 83-90.

- - $1972 \mathrm{~h}$. - Observations sur le cycle biologique de l'Ascaride Polydelphis quadrangularis (Schneider, 1866) parasite du serpent crotale. Ann. Parasitol. hum. comp., 47, 91-120.

- - 1973. - Fase migratória tecidual de Ascaris suum Goeze, 1782 : estudo experimental relativo a modificações cuticulares de suas larvas. São Paulo. 113 p. (Thèse).

— - 1975. - Dimorphisme sexuel de l'ébauche génitale et de la queue chez des larves d'Ascaris suum au $3^{\circ}$ stade. Ann. Parasitol. hum. comp., 50, 167-172.

BaIN (O.), 1970. - Cycle Evolutif de l'Heterakidae Strongyluris brevicaudata (Nematoda). Mise en évidence de deux mues dans l'œuf. Ann. Parasitol. hum., comp., 45, 637653.

Graeiro (A.), 1973. - Communication personnelle.

HENNER (S.), 1959. - Untersuchungen über Häutungen von Larven verschiedner Askaridenarten während ihrer präparasitischen Phase, München. 37 p. (Inaugural-Dissertation). 
HeRd (R. P.) et MACNaught (D. J.), 1975. - Arrested development and the histotropic phase of Ascaridia galli in the chicken. Internat. J. Parasit., 5, 401-406.

MAUNG (M.), 1975. - Studies on speciation of some of the ascaridoid nematodes of mammals and reptiles, University of Queensland, Brisbane ( $\mathrm{Ph}$. D. Thesis).

RoBERTS (F. H. S.), 1937. - Studies on the biology and control of the large roundworm of fowls Ascaridia galli (Schrank, 1788) Freeborn, 1923. Animal Health Sta. Yeerongpilly, Queensland, bull., 2, 106.

THust (R.), 1968. - Submikroskopische Untersuchungen über die Morphogenese des Integumentes von Ascaris lumbricoides L., 1758. Z. wiss. Zool., Abt. A, 178, 1-39.

Tugwell (R. L.) et Ackert (J.E.), 1952. - On the tissue phase of the life cycle of the fowl nematode Ascaridia galli (Schrank). J. Parasit., 38, 277-288. 